\title{
Parameters of fit and intermediate solutions in multi-value Qualitative Comparative Analysis
}

\author{
Alrik Thiem
}

Published online: 8 March 2014

(C) Springer Science+Business Media Dordrecht 2014

\begin{abstract}
Multi-value Qualitative Comparative Analysis (mvQCA) is a variant of QCA that continues to exist under the shadow of crisp and fuzzy-set QCA. The lack of support for parameters of fit and intermediate solutions has contributed to this undeserved status. This article introduces two innovations that put mvQCA on a par with its two sister variants. First, consistency and coverage as the two most important parameters of fit are generalized. Second, the concepts of easy and difficult counterfactuals for deriving intermediate solutions are imported. I demonstrate how to leverage these features in the QCA software package for the R environment. For researchers who do not use QCA, I explain how to exploit VeitchKarnaugh maps instead for solving set-theoretic minimization problems of low to moderate complexity.
\end{abstract}

Keywords Configurational comparative methods - Consistency · Coverage - csQCA · fsQCA · mvQCA · QCA · Qualitative Comparative Analysis

\section{Introduction}

Multi-value Qualitative Comparative Analysis (mvQCA) has long led a niche existence under the shadow of its two sister variants crisp-set QCA (csQCA) and fuzzy-set QCA (fsQCA). Although Rihoux et al (2013, p. 177) speak of an upward trend, the comprehensive COMPASSS bibliographic database reveals that, out of currently 347 applications of QCA in peer-reviewed academic journals since 1984, the share of mvQCA amounts to a meagre 2.9 per cent and is, if anything, on the decline again. For a method that was introduced as a promising generalization of csQCA at about the same time as fsQCA, this figure is

\footnotetext{
A. Thiem $(\varangle)$

Department of Philosophy, University of Geneva, Rue de Candolle 2 / Bât.

Landolt, 1211 Geneva, Switzerland

e-mail: alrik.thiem@gmail.com
} 
surprisingly low. ${ }^{1}$ Despite its disproportionate application ratio, however, research across an impressive diversity of fields has made successful use of the opportunities offered by mvQCA.

For example, Ackrén and Olausson (2008) apply mvQCA to analyse the factors driving island autonomy. Hartmann and Kemmerzell (2010) and Berg-Schlosser (2008) use it to answer questions about party tolerance and democratic success in Africa, Mannewitz (2010) to examine the trajectory of post-communist parties in Central and Eastern Europe, and Klüver (2010) to explain why national interest groups engage in lobbying activities at the European level. Sager and Andereggen (2012) investigate transport projects in Switzerland by means of mvQCA, while Balthasar (2006) employs it to understand the use of project evaluations. Huntjens et al. (2011) draw on mvQCA to find out which regime characteristics are related to policy learning in river basin management. And Gross and Garvin (2011) as well as Delhi et al. (2012) study public-private partnership governance of infrastructure projects with the help of mvQCA. In summary, although the method has so far been employed relatively rarely, this brief review clearly attests to its applicability across a broad diversity of areas. The argument that few research questions have lent themselves to the use of mvQCA thus does not hold together.

Another potential reason why mvQCA has remained undervalued may be found in the highly sceptical stance leading methodologists have taken on this variant (Schneider and Wagemann 2012, pp. 258-263; Vink and van Vliet 2009, 2013), which seems to have deterred potential end-users from applying it. ${ }^{2}$ In addition, the method has been lacking certain capabilities which both csQCA and fsQCA possess. In particular, users have been missing parameters of fit such as consistency and coverage - fundamental summary statistics for assessing set-theoretic hypotheses - and the possibility for deriving intermediate solutions (e.g. Jordan et al. 2011, p. 1166). The objective of this article is to import these two features into mvQCA. Although they are conceptually independent, their integrated use warrants a unified treatment. By putting mvQCA on a par with its two sister variants in terms of capabilities, any remaining doubts about the method's usefulness should also be dispelled.

The article is structured as follows. In Sect. 2, I review the theoretical basics of mvQCA and briefly introduce the recent study by Sager and Andereggen (2012) on 17 cases of Swiss transport policy, which will later be used for demonstrating the innovations presented herein. In addition, I establish the system of notation to be employed throughout the article. In Sect. 3, I first revisit the concepts of consistency and coverage as developed for csQCA, and subsequently extend them to the case of mvQCA. The same approach is taken in Sect. 4, where the procedure for generating intermediate solutions in csQCA is summarized before its extension to mvQCA is elaborated on. Lastly, in Sect. 5, I illustrate the use of the QCA software - a versatile command-line interface package for the R environment-with respect to parameters of fit and intermediate solutions in mvQCA. ${ }^{3}$ For researchers who prefer other software that lacks such functionality, I explain how to derive intermediate solutions manually by means of Veitch-Karnaugh maps-a well-known minimization device from switching circuit theory for moderately complex problems. The conclusions recapitulate the argument, delineate further potential for future methodological developments, and offer some predictions concerning the use of mvQCA in applied research.

\footnotetext{
${ }^{1}$ See http://www.compasss.org/bibdata.htm. Accessed $15 \mathrm{Feb} 2014$. The application share of fsQCA is about $36.9 \%$, that of csQCA about $60.2 \%$.

2 Note that the recent exchange between Denk (2010) and Rohlfing (2012) on "multi-level" QCA is unrelated to multi-value QCA.

${ }^{3}$ A sans-serif type face indicates a piece of software and a typewriter font face commands, functions and objects that are part of a software.
} 


\section{Basics of mvQCA}

The method of mvQCA, together with the tailored computer programme Tosmana, was introduced by Lasse Cronqvist at about the same time when fsQCA was developed and became available in software (Cronqvist and Berg-Schlosser 2009; Cronqvist 2011; Ragin 2000). So far, however, mvQCA has neither found much favour with applied researchers nor with the majority of methodologists, the latter of whom have not only long been very sceptical about its potential for adding anything to what could already be achieved with csQCA and fsQCA, but who have also doubted its status as a set-theoretic method more generally (Schneider and Wagemann 2012; Vink and van Vliet 2009). This negative view seems to have had a deterrence effect on applied researchers and potential users (e.g., Hartmann and Kemmerzell 2010, p. 645). Moreover, attempts at positioning mvQCA between csQCA and fsQCA with respect to ranges of case numbers have neither been methodologically convincing nor successful in countering prevailing hesitations (Herrmann and Cronqvist 2009; Rihoux 2006, p. 686). By clarifying the formal relations between different QCA variants, more recent work on mvQCA has been considerably more positive (Thiem 2013a,b). I will thus only review the method's basic principles here without broaching the technicalities of this debate and refer interested readers to the above-mentioned sources for more details.

In contrast to csQCA, which is based on Boolean logic, and fsQCA, which currently still follows fuzzy logic in the set type it processes but Boolean logic in its minimization procedure, mvQCA builds on multivalent logic. ${ }^{4}$ Fuzzy and multivalent logic each provide separate extensions to the Boolean case in which many of the latter's axioms are no longer valid. But there exists a single core principle that unites all QCA variants: the systematic minimization of the output function. ${ }^{5}$ This process is predicated on the principle that, if a union of at least two unique intersections, all of which exhibit the same output function value, agree on the levels of all condition factors but one, and if all the levels of this one condition factor are represented in the union, then it is redundant with respect to the level of the outcome factor on which the common output function value is based.

A generic example serves to illustrate this principle. Consider the following scenario with three condition factors $\mathbf{A}, \mathbf{B}$ and $\mathbf{C}$. The former two possess two levels: $\{0\}$ and $\{1\}$; the latter three levels: $\{0\},\{1\}$ and $\{2\}$. The outcome factor $\mathbf{O}$ also has three levels: $\{0\},\{1\}$ and $\{2\}{ }^{6}$ By convention, the intersection operator " $\cap$ " between individual factor levels will not be written out. A consistent subset relation constituting an output function with respect to $\mathbf{O}^{\{1\}}$ could then be given by set relation (1):

$$
\mathbf{A}^{\{0\}} \mathbf{B}^{\{1\}} \mathbf{C}^{\{0\}} \cup \mathbf{A}^{\{0\}} \mathbf{B}^{\{1\}} \mathbf{C}^{\{1\}} \cup \mathbf{A}^{\{0\}} \mathbf{B}^{\{1\}} \mathbf{C}^{\{2\}} \subseteq \mathbf{O}^{\{1\}}
$$

Relation (1) can be simplified according to the principle described above since all levels of $\mathbf{C}$ are present and the respective levels of $\mathbf{A}$ and $\mathbf{B}$ are constant across all intersections in this union. More precisely, set relation (1) can be reduced successively to set relation (5):

\footnotetext{
4 Multivalent logic requires a significant generalization of Boolean algebra, particularly if both condition and outcome factors are allowed to assume multivalent structures. See Dubrova (2002) for a comprehensive but technical introduction.

5 Some authors have proposed alternative minimization procedures that do not explicitly use this core mechanism (e.g. Baumgartner 2009; Eliason and Stryker 2009; Thiem and Duşa forthcoming). I do not discuss them here.

6 The QCA package to be introduced later in Sect. 5.1 is the only software so far than can process outcome factors with multiple levels directly. In Tosmana, such factors have to be dichotomized before the analysis (Cronqvist and Berg-Schlosser 2009, p. 84).
} 


$$
\begin{aligned}
\mathbf{A}^{\{0\}} \mathbf{B}^{\{1\}} \mathbf{C}^{\{0\}} \cup \mathbf{A}^{\{0\}} \mathbf{B}^{\{1\}} \mathbf{C}^{\{1\}} \cup \mathbf{A}^{\{0\}} \mathbf{B}^{\{1\}} \mathbf{C}^{\{2\}} & \subseteq \mathbf{O}^{\{1\}} \\
\mathbf{A}^{\{0\}} \mathbf{B}^{\{1\}}\left(\mathbf{C}^{\{0\}} \cup \mathbf{C}^{\{1\}} \cup \mathbf{C}^{\{2\}}\right) & \subseteq \\
\mathbf{A}^{\{0\}} \mathbf{B}^{\{1\}}(1) & \subseteq \\
\mathbf{A}^{\{0\}} \mathbf{B}^{\{1\}} & \subseteq \mathbf{O}^{\{1\} .}
\end{aligned}
$$

Condition factor $\mathbf{C}$ is redundant and can therefore be eliminated. If not all levels of $\mathbf{C}$ had been present in (1), no reduction would have been possible. Reduction in mvQCA thus generalizes the equivalent procedure in csQCA and fsQCA, in which both condition and outcome factors always comprise only two levels. ${ }^{7}$

In order to demonstrate the ideas to be introduced in this article, I will draw on the recent mvQCA study of 17 Swiss transport projects by Sager and Andereggen (2012). ${ }^{8}$ In this study, the authors implement a two-staged analysis of high project acceptance as a function of a set of five contextual and four polity condition factors. I will focus on the first stage of their analysis involving only the contextual factors. These are the administrative level on which the project was implemented, $\mathbf{L}$, with the following levels: $\{2\}$ federal, $\{1\}$ cantonal, $\{0\}$ municipal; the financial situation of the main stakeholders, $\mathbf{F}$, with levels: $\{1\}$ positive, $\{0\}$ negative; the sociocultural location of the project, $\mathbf{U}$, with levels: $\{1\}$ urban, $\{0\}$ rural; the cultural location of the project, $\mathbf{D}$, with levels: $\{1\}$ German-speaking region, $\{0\}$ Frenchspeaking region; and the project background, $\mathbf{H}$, with levels: $\{1\}$ prior history, $\{0\}$ no prior history. The outcome factor, $\mathbf{A}$, measures the degree of acceptance with which the project has met and comprises the following two levels: $\{1\}$ high, $\{0\}$ low. ${ }^{9}$ In summary, the dataset contains one trivalent condition factor $(\mathbf{L})$, four bivalent condition factors $(\mathbf{F}, \mathbf{U}, \mathbf{D}, \mathbf{H})$ and a single bivalent outcome factor (A). ${ }^{10}$ It is shown in Table 1.

\section{Parameters of fit in mvQCA}

Parameters of fit are important summary statistics in evaluating the exact structure of settheoretic relations. Two such statistics have been introduced by Ragin (2006) in order to describe the pattern between a condition $\mathbf{X}^{\{\cdot\}}$ and an outcome $\mathbf{Y}^{\{\cdot\}}$ in set-theoretic terms, where $\{\cdot\}$ is a generic label for the set formed by the level of the condition / outcome factor. Usually, these are " 1 " for the presence of some condition or outcome and " 0 " for their absence. ${ }^{11}$ First, consistency measures the degree to which a perfect subset or superset relation between some simple or complex condition $\mathbf{X}^{\{\cdot\}}$ and a simple or complex outcome $\mathbf{Y}^{\{\cdot\}}$ exists. ${ }^{12}$ Second, coverage provides valuable information about the internal structure of consistent set relations. More precisely, it measures the relative coincidence of $\mathbf{Y}^{\{\cdot\}}$ and $\mathbf{X}^{\{\cdot\}}$. For example,

\footnotetext{
7 Note that not all minimization algorithms in QCA follow this pairwise elimination procedure since it is computationally highly demanding and thus not very efficient. For example, both the QCA package and Tosmana use different algorithms.

8 As Sager and Andereggen (2012, p. 70) in fact present incorrect solutions in their original article, I will also correct these along the way.

${ }^{9}$ For reasons of space and layout, I use acronyms other than those in the original study.

10 The terms bivalent, trivalent, etc. specify the number of levels a factor is comprised of.

11 Although Ragin has introduced these statistics in relation to fsQCA, they apply equally to csQCA in their set membership score form, but not their level indicator form. However, since mvQCA generalizes csQCA, not fsQCA, I use the simple level indicator form here.

12 So far, only simple outcomes have been analysed in QCA, but there exists no reason why consistency could not be extended to complex outcomes.
} 
Table 1 Reduced dataset from Sager and Andereggen (2012) on Swiss transport projects

\begin{tabular}{llllllll}
\hline Project & Abbr. & L & H & G & U & F & A \\
\hline Bypass Lungern & Lung & 2 & 0 & 1 & 0 & 1 & 1 \\
Pfynwald & Pfyn & 1 & 1 & 1 & 0 & 1 & 1 \\
Car Park Berntor Solothurn 1 & Sol1 & 0 & 1 & 1 & 1 & 1 & 1 \\
Car Park Berntor Solothurn 2 & Sol2 & 0 & 1 & 1 & 1 & 1 & 1 \\
Supportive Measures Zurich West & ZurW & 1 & 0 & 1 & 1 & 1 & 1 \\
Tramline Claragraben Basel 1 & TrB1 & 1 & 0 & 1 & 1 & 1 & 0 \\
Tramline Claragraben Basel 2 & TrB2 & 1 & 1 & 1 & 1 & 0 & 0 \\
Green Line Commuter Train Basel 1 & GrB1 & 1 & 0 & 1 & 1 & 1 & 0 \\
Green Line Commuter Train Basel 2 & GrB2 & 1 & 1 & 1 & 1 & 0 & 1 \\
Loetschberg Basic Tunnel Raron & Loet & 2 & 0 & 1 & 0 & 0 & 1 \\
Locarno Bypass & Loca & 1 & 1 & 0 & 1 & 1 & 0 \\
Seftigenstrasse Wabern & Wabr & 1 & 0 & 1 & 1 & 0 & 1 \\
LEB Commuter Train Lausanne 1 & Lau1 & 0 & 1 & 0 & 1 & 0 & 0 \\
LEB Commuter Train Lausanne 2 & Lau2 & 0 & 1 & 0 & 1 & 1 & 1 \\
RER La Plaine Geneve & Gene & 1 & 1 & 0 & 1 & 1 & 1 \\
T10 Bypass Gampelen & Gamp & 1 & 1 & 1 & 0 & 0 & 0 \\
Vereinatunnel Closters & Clos & 1 & 1 & 1 & 0 & 1 & 1 \\
Délemont Bypass & Delm & 1 & 1 & 0 & 1 & 0 & 0 \\
TCSP Tramline Geneva & TtGe & 1 & 1 & 0 & 1 & 0 & 0 \\
Wagen-Eschenbach-Schmerikon Bypass & Wagn & 1 & 0 & 1 & 0 & 1 & 0 \\
Schulhausplatz Baden & Badn & 1 & 1 & 1 & 1 & 1 & 1 \\
\hline & & & & & & \\
\hline
\end{tabular}

if $\mathbf{X}^{\{\cdot\}}$ contains all elements of $\mathbf{Y}^{\{\cdot\}}$ plus some others, the former is a perfectly consistent superset of the latter, but their relative coincidence is not unity. Put differently, $\mathbf{Y}^{\{\cdot\}}$ does not possess perfect "empirical relevance" with respect to $\mathbf{X}^{\{\cdot\}}$ (Ragin 2006, p. 292). To summarize, consistency and coverage complement each other in a hierarchical manner, with the former taking precedence over the latter.

Almost all applied QCA research that has appeared since then has made use of consistency and coverage, not least because it is now computed by default in the popular fs/QCA software (Ragin and Davey 2009). But as Jordan et al. (2011, p. 1166) have noted in their comprehensive review, "[a] definition of consistency for the mvQCA method has not yet been developed", and, by implication, nor a definition of coverage. This lack is unfortunate since these parameters increase the sophistication of QCA applications considerably. In the remainder of this section, I will close this gap by extending both consistency and coverage from the bivalent to the multivalent case.

The concept of sufficiency of condition $\mathbf{X}^{\{\cdot\}}$ with respect to outcome $\mathbf{Y}^{\{\cdot\}}$ requires a subset relation between them. In contrast, the concept of necessity requires a superset relation. Condition $\mathbf{X}^{\{\cdot\}}$ is necessary and sufficient with respect to $\mathbf{Y}^{\{\cdot\}}$ only if the former stands in both a subset and a superset relation to the latter. This requirement is fulfilled if $\mathbf{X}^{\{\cdot\}}$ and $\mathbf{Y}^{\{\cdot\}}$ are identical with respect to their elements. As a result, the two parameters of fit and the two basic types of set relations combine to sufficiency consistency, necessity coverage, necessity consistency and sufficiency coverage. But these four combinations are not independent of each other. 
Table 2 Contingency tables in csQCA and mvQCA

\begin{tabular}{|c|c|c|c|c|c|c|c|}
\hline \multirow{8}{*}{$\mathbf{Y}$} & $\left\{v_{p}\right\}$ & $n_{1 ; p}$ & $n_{2 ; p}$ & $n_{\cdot ; p}$ & $n_{j ; p}$ & $n_{\cdot ; p}$ & $n_{p ; p}$ \\
\hline & $\{v \cdot\}$ & $n_{1 ;}$ & $n_{2 ;}$ & $n_{\cdot ; \cdot}$ & $n_{j ;}$ & $n_{\cdot ;}$ & $n_{p ;}$ \\
\hline & $\left\{v_{j}\right\}$ & $n_{1 ; j}$ & $n_{2 ; j}$ & $n_{\cdot ; j}$ & $n_{j ; j}$ & $n \cdot ; j$ & $n_{p ; j}$ \\
\hline & $\{v \cdot\}$ & $n_{1}$ & $n_{2 ;}$ & $n_{\cdot ;}$ & $n_{j ;}$ & $n_{\cdot ; \cdot}$ & $n_{p}$ \\
\hline & $\left\{v_{2}\right\}$ & $n_{1 ; 2}$ & $n_{2 ; 2}$ & $n_{\cdot ; 2}$ & $n_{j ; 2}$ & $n_{\cdot ; 2}$ & $n_{p ; 2}$ \\
\hline & $\left\{v_{1}\right\}$ & $n_{1 ; 1}$ & $n_{2 ; 1}$ & $n_{\cdot ; 1}$ & $n_{j ; 1}$ & $n_{\cdot ; 1}$ & $n_{p ; 1}$ \\
\hline & & $\left\{v_{1}\right\}$ & $\left\{v_{2}\right\}$ & $\{v\}$. & $\left\{v_{j}\right\}$ & $\{v \cdot\}$ & $\left\{v_{p}\right\}$ \\
\hline & & & & & & & \\
\hline
\end{tabular}

Sufficiency consistency $\mathrm{Con}_{\mathrm{S}}$ measures the degree to which a subset relation between $\mathbf{X}^{\{\cdot\}}$ and $\mathbf{Y}^{\{\cdot\}}$ exists, or put differently, to which extent the elements in the former set are also elements in the latter set. It is mirrored by necessity coverage $\operatorname{Cov}_{\mathrm{N}}$, which measures the degree to which an identity relation between $\mathbf{Y}^{\{\cdot\}}$ and $\mathbf{X}^{\{\cdot\}}$ exists, or put differently, to which extent the elements in the former set are also elements in the latter set. Their formula is given in Eq. (6):

$$
\operatorname{Con}_{\mathrm{S}}\left(\mathbf{X}^{\{\cdot\}} \subseteq \mathbf{Y}^{\{\cdot\}}\right)=\operatorname{Cov}_{\mathrm{N}}\left(\mathbf{X}^{\{\cdot\}} \supseteq \mathbf{Y}^{\{\cdot\}}\right)=\frac{\sum_{i=1}^{n} \mathbf{Y}^{\{\cdot\}}=1 \mid \mathbf{X}^{\{\cdot\}}=1}{\sum_{i=1}^{n} \mathbf{X}^{\{\cdot\}}=1}
$$

Conversely, sufficiency coverage $\operatorname{Cov}_{\mathrm{S}}$ measures the degree to which an identity relation between $\mathbf{X}^{\{\cdot\}}$ and $\mathbf{Y}^{\{\cdot\}}$ exists. It is mirrored by necessity consistency $\operatorname{Con}_{\mathrm{N}}$, which measures the degree to which a subset relation between $\mathbf{Y}^{\{\cdot\}}$ and $\mathbf{X}^{\{\cdot\}}$ exists. The formula for these parameters is given in Eq. (7):

$$
\operatorname{Con}_{\mathrm{N}}\left(\mathbf{X}^{\{\cdot\}} \supseteq \mathbf{Y}^{\{\cdot\}}\right)=\operatorname{Cov}_{\mathrm{S}}\left(\mathbf{X}^{\{\cdot\}} \subseteq \mathbf{Y}^{\{\cdot\}}\right)=\frac{\sum_{i=1}^{n} \mathbf{X}^{\{\cdot\}}=1 \mid \mathbf{Y}^{\{\cdot\}}=1}{\sum_{i=1}^{n} \mathbf{Y}^{\{\cdot\}}=1}
$$

In the case of csQCA, there are thus four quantities of interest, each of which corresponds to one cell of a $2 \times 2$ table as shown in the lower left quadrant of Table 2 as marked by a dark-grey cell background ( $)$. If the factor levels under investigation are given by $\left\{v_{2}\right\}$, denoting the second level of each factor, then Eqs. (6) and (7) can be written in aggregated form as Eqs. (8) and (9), respectively:

$$
\begin{gathered}
\operatorname{Con}_{\mathrm{S}}\left(\mathbf{X}^{\left\{v_{2}\right\}} \subseteq \mathbf{Y}^{\left\{v_{2}\right\}}\right)=\operatorname{Cov}_{\mathrm{N}}\left(\mathbf{X}^{\left\{v_{2}\right\}} \supseteq \mathbf{Y}^{\left\{v_{2}\right\}}\right)=\frac{n_{2 ; 2}}{n_{2 ; 2}+n_{2 ; 1}}, \\
\operatorname{Con}_{\mathrm{N}}\left(\mathbf{X}^{\left\{v_{2}\right\}} \supseteq \mathbf{Y}^{\left\{v_{2}\right\}}\right)=\operatorname{Cov}_{\mathrm{S}}\left(\mathbf{X}^{\left\{v_{2}\right\}} \subseteq \mathbf{Y}^{\left\{v_{2}\right\}}\right)=\frac{n_{2 ; 2}}{n_{2 ; 2}+n_{1 ; 2}} .
\end{gathered}
$$

It is now easy to see how Eqs. (8) and (9) can be extended beyond two levels to the case in which $\mathbf{X}$ and $\mathbf{Y}$ comprise exactly $p_{\mathbf{X}}$ and $p_{\mathbf{Y}}$ levels, thereby increasing the table's dimensions from $2 \times 2$ to $p_{\mathbf{X}} \times p_{\mathbf{Y}}$. For any specific level $j_{\mathbf{X}}=\mathrm{a}$ of condition factor $\mathbf{X}$ and $j_{\mathbf{Y}}=\mathrm{b}$ of outcome factor $\mathbf{Y}$, Eqs. (8) and (9) can be generalized to Eqs. (10) and (11), respectively: 
Table 3 Truth table of data from Sager and Andereggen (2012)

\begin{tabular}{llllllllll}
\hline $\mathcal{C}_{i}$ & $\mathbf{L}$ & $\mathbf{H}$ & $\mathbf{G}$ & $\mathbf{U}$ & $\mathbf{F}$ & OUT & $n$ & Con $_{\mathrm{S}}$ & Cases \\
\hline 1 & 0 & 1 & 0 & 1 & 0 & 0 & 1 & 0.000 & Lau1 \\
2 & 0 & 1 & 0 & 1 & 1 & 1 & 1 & 1.000 & Lau2 \\
3 & 0 & 1 & 1 & 1 & 1 & 1 & 2 & 1.000 & Sol1, Sol2 \\
4 & 1 & 0 & 1 & 0 & 1 & 0 & 1 & 0.000 & Wagn \\
5 & 1 & 0 & 1 & 1 & 0 & 1 & 1 & 1.000 & Wabr \\
6 & 1 & 0 & 1 & 1 & 1 & 0 & 3 & 0.333 & ZurW, TrB1, GrB1 \\
7 & 1 & 1 & 0 & 1 & 0 & 0 & 2 & 0.000 & Delm, TtGe \\
8 & 1 & 1 & 0 & 1 & 1 & 0 & 2 & 0.500 & Loca, Gene \\
9 & 1 & 1 & 1 & 0 & 0 & 0 & 1 & 0.000 & Gamp \\
10 & 1 & 1 & 1 & 0 & 1 & 1 & 2 & 1.000 & Pfyn, Clos \\
11 & 1 & 1 & 1 & 1 & 0 & 0 & 2 & 0.500 & TrB2, GrB2 \\
12 & 1 & 1 & 1 & 1 & 1 & 1 & 1 & 1.000 & Badn \\
13 & 2 & 0 & 1 & 0 & 0 & 1 & 1 & 1.000 & Loet \\
14 & 2 & 0 & 1 & 0 & 1 & 1 & 1 & 1.000 & Lung \\
$\vdots$ & $\vdots$ & $\vdots$ & $\vdots$ & $\vdots$ & $\vdots$ & $?$ & - & - & logical remainders \\
\hline
\end{tabular}

$$
\begin{aligned}
& \operatorname{Con}_{\mathrm{S}}\left(\mathbf{X}^{\left\{v_{\mathrm{a}}\right\}} \subseteq \mathbf{Y}^{\left\{v_{\mathrm{b}}\right\}}\right)=\operatorname{Cov}_{\mathrm{N}}\left(\mathbf{X}^{\left\{v_{\mathrm{a}}\right\}} \supseteq \mathbf{Y}^{\left\{v_{\mathrm{b}}\right\}}\right)=\frac{n_{\mathrm{a} ; \mathrm{b}}}{\sum_{j=1}^{p_{\mathbf{Y}}} n_{\mathrm{a} ; j}}, \\
& \operatorname{Con}_{\mathrm{N}}\left(\mathbf{X}^{\left\{v_{\mathrm{a}}\right\}} \supseteq \mathbf{Y}^{\left\{v_{\mathrm{b}}\right\}}\right)=\operatorname{Cov}_{\mathrm{S}}\left(\mathbf{X}^{\left\{v_{\mathrm{a}}\right\}} \subseteq \mathbf{Y}^{\left\{v_{\mathrm{b}}\right\}}\right)=\frac{n_{\mathrm{a} ; \mathrm{b}}}{\sum_{j=1}^{p_{\mathbf{X}}} n_{j ; \mathrm{b}}} .
\end{aligned}
$$

The crucial regions for Eqs. (10) and (11) are marked by a light-grey cell background in Table $2(\square)$. Since any level can be substituted for $j_{\mathbf{X}}$ and $j_{\mathbf{Y}}$, Eqs. (10) and (11) generalize consistency and coverage from the bivalent to the multivalent case, and so allow their use in csQCA as well as mvQCA. ${ }^{13}$

When Eq. 10 is applied to the data analysed in Sager and Andereggen (2012), the truth table presented in Table 3 results. For each observed configuration given in $\mathcal{C}_{1}$ to $\mathcal{C}_{14}$, a sufficiency consistency score can be computed, which is listed under column "Con S". For example, Con $_{\mathrm{S}}\left(\mathcal{C}_{6}\right)=0.333$ because the project ZurW enjoyed high acceptance, in contrast to projects TrB1 and GrB1. The column "OUT" provides the consistency-based function value for each configuration. A configuration is coded positive (" 1 ") only if it forms a perfect subset of the outcome $\mathbf{A}^{\{1\}}$ as indicated by a unity consistency score, otherwise it is coded negative ("0"). ${ }^{14}$ The column " $n$ " shows the total number of cases for each configuration.

\footnotetext{
13 Similarly, the number of configurations $d$ that can be formed from $k$ conditions factors with $p_{j}$ levels is given by $d=\prod_{j=1}^{k} p_{j}$, which reduces to $d=2^{k}$ for csQCA as all condition factors are bivalent.

14 Configurations $\mathcal{C}_{8}$ and $\mathcal{C}_{11}$ could be coded as so-called contradictions (not to be confused with contradiction in the logical sense of the word) since their cases display the outcome as often as its negation. The possibility for contradictions has been excluded for reasons of simplicity. The Tosmana software would have automatically coded configurations $\mathcal{C}_{6}, \mathcal{C}_{8}$ and $\mathcal{C}_{11}$ as contradictions.
} 


\section{Intermediate solutions in mvQCA}

The literature distinguishes between three distinct solutions types in QCA: complex, parsimonious and intermediate (Ragin and Sonnett 2005; Ragin 2008, pp. 160-175). Complex solutions are also called conservative because they only take into account what has been observed, not what is possible but unobserved (Ragin 1987, p. 105; Schneider and Wagemann 2012, p. 162). ${ }^{15}$ Only empirical configurations thus enter the minimization process. In contrast, parsimonious solutions make the most liberal use of logical remainders by allowing as many simplifying assumptions as needed in order to reduce an output function to its simplest equivalent. ${ }^{16}$ Simplifying assumptions are those logical remainders that have contributed to a more parsimonious solution. Intermediate solutions seek to strike a balance between these two extremes by making only those simplifying assumptions available for reduction that represent easy counterfactuals from the theoretical perspective of the analyst. In contrast, simplifying assumptions that represent difficult counterfactuals are barred from inclusion in the output function and do not enter minimization. As a result, the derivation of intermediate solutions necessitates the prior derivation, run quietly or otherwise, of a conservative and a parsimonious solution. ${ }^{17}$

The process of separating easy from difficult counterfactuals in the set of simplifying assumptions is controlled by a condition's hypothesized effect with respect to the outcome under consideration. In QCA, these auxiliary hypotheses are referred to as directional expectations. These expectations can take three forms in csQCA: a condition can be associated with the outcome, the negation of this condition can be associated with the outcome, or either can plausibly be associated with the outcome.

Consider the hypothetical situation in Fig. 1, where $\mathbf{A}^{\{0\}} \mathbf{B}^{\{1\}} \mathbf{D}^{\{1\}} \mathbf{E}^{\{0\}}$ has been identified as the minimal union of the conservative solution. ${ }^{18}$ Both $\mathbf{D}^{\{1\}}$ and $\mathbf{E}^{\{1\}}$ are expected to be associated with $\mathbf{O}^{\{1\}}$, not their negations $\mathbf{D}^{\{0\}}$ and $\mathbf{E}^{\{0\}}$, whereas no directional expectations are formulated for $\mathbf{A}$ and $\mathbf{B}$. The minimal union of the parsimonious solution is given by $\mathbf{A}^{\{0\}} \mathbf{B}^{\{1\}}$. The minimal unions of the conservative and the parsimonious solution thus form the extremes of a continuum over which other minimal unions of solutions are possible. These other unions are supersets of the minimal union of the conservative solution, but subsets of the minimal union of the parsimonious solution. The crucial question is which minimal unions of intermediate solutions in the set of all possible such minimal unions represent plausible scenarios with respect to the outcome.

The first intermediate solution, $\mathbf{A}^{\{0\}} \mathbf{B}^{\{1\}} \mathbf{D}^{\{1\}}$, results from the addition of the simplifying assumption $\mathbf{A}^{\{0\}} \mathbf{B}^{\{1\}} \mathbf{D}^{\{1\}} \mathbf{E}^{\{1\}}$ to the output function of the conservative solution. But if $\mathbf{A}^{\{0\}} \mathbf{B}^{\{1\}} \mathbf{D}^{\{1\}} \mathbf{E}^{\{0\}}$ is empirically associated with $\mathbf{O}^{\{1\}}$, then any non-observed configuration that only differs on $\mathbf{E}$ in that $\mathbf{E}^{\{0\}}$ is replaced by $\mathbf{E}^{\{1\}}$ must also be counterfactually associated with $\mathbf{O}^{\{1\}}$ if the directional expectation associates $\mathbf{E}^{\{1\}}$ with $\mathbf{O}^{\{1\}}$. The logical remainder

\footnotetext{
15 I will use the term conservative rather than complex because it is closer to the definition of this solution type.

16 In the Quine-McCluskey algorithm, for example, this procedure works in two steps. First, all logical remainder configurations are added to the output function. Second, after the prime implicants have been derived, these configurations are removed again from the prime implicant chart before the solution is finalized (Ragin 1987, p. 110).

17 Schneider and Wagemann (2013) propose TESA — theory-enhanced standard analysis—which consists in breaking the algorithmic link between simplifying assumptions, easy and difficult counterfactuals in the derivation of parsimonious and intermediate solutions.

18 From a formal point of view, only solutions with more than one prime implicant are causally interpretable (Baumgartner 2009). I disregard this requirement here for reasons of simplicity.
} 


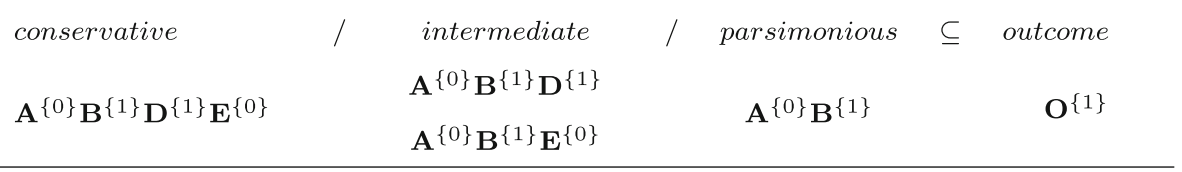

Fig. 1 Intermediate solutions between conservative and parsimonious solution

Table 4 Solutions types and simplifying assumptions with respect to $\mathbf{A}^{\{1\}}$

\begin{tabular}{llll}
\hline ID & $S_{\mathrm{CO}}$ & $S_{\mathrm{IN}}$ & $S_{\mathrm{PA}}$ \\
\hline 1 & $\mathbf{L}^{\{0\}} \mathbf{H}^{\{1\}} \mathbf{U}^{\{1\}} \mathbf{F}^{\{1\}}$ & $\mathbf{H}^{\{1\}} \mathbf{G}^{\{1\}} \mathbf{F}^{\{1\}}$ & $\mathbf{L}^{\{2\}}$ \\
2 & $\mathbf{L}^{\{1\}} \mathbf{H}^{\{1\}} \mathbf{G}^{\{1\}} \mathbf{F}^{\{1\}}$ & $\mathbf{L}^{\{0\}} \mathbf{H}^{\{1\}} \mathbf{F}^{\{1\}}$ & $\mathbf{H}^{\{0\}} \mathbf{F}^{\{0\}}$ \\
3 & $\mathbf{L}^{\{2\}} \mathbf{H}^{\{0\}} \mathbf{G}^{\{1\}} \mathbf{U}^{\{0\}}$ & $\mathbf{L}^{\{2\}} \mathbf{G}^{\{1\}} \mathbf{U}^{\{0\}}$ & $\mathbf{L}^{\{0\}} \mathbf{F}^{\{1\}}$ \\
4 & $\mathbf{L}^{\{1\}} \mathbf{H}^{\{0\}} \mathbf{G}^{\{1\}} \mathbf{U}^{\{1\}} \mathbf{F}^{\{0\}}$ & $\mathbf{L}^{\{1\}} \mathbf{H}^{\{0\}} \mathbf{G}^{\{1\}} \mathbf{F}^{\{0\}}$ & $\mathbf{H}^{\{1\}} \mathbf{G}^{\{1\}} \mathbf{F}^{\{1\}}$ \\
1 & Easy counterfactuals & $\mathbf{L}^{\{0\}} \mathbf{H}^{\{1\}} \mathbf{U}^{\{0\}} \mathbf{F}^{\{1\}}$ & $\mathbf{L}^{\{0\}} \mathbf{H}^{\{0\}}$ \\
2 & & $\mathbf{L}^{\{2\}} \mathbf{H}^{\{1\}} \mathbf{G}^{\{1\}} \mathbf{F}^{\{1\}}$ & $\mathbf{L}^{\{2\}} \mathbf{G}^{\{0\}}$ \\
3 & & $\mathbf{L}^{\{2\}} \mathbf{H}^{\{1\}} \mathbf{G}^{\{1\}} \mathbf{U}^{\{0\}}$ & $\mathbf{L}^{\{2\}} \mathbf{H}^{\{1\}}$ \\
4 & $\mathbf{L}^{\{1\}} \mathbf{H}^{\{0\}} \mathbf{G}^{\{1\}} \mathbf{U}^{\{0\}} \mathbf{F}^{\{0\}}$ & $\mathbf{L}^{\{2\}} \mathbf{U}^{\{1\}}$ \\
5 & & $\mathbf{L}^{\{2\}} \mathbf{H}^{\{0\}} \mathbf{G}^{\{1\}} \mathbf{U}^{\{1\}} \mathbf{F}^{\{0\}}$ & $\mathbf{H}^{\{0\}} \mathbf{G}^{\{0\}} \mathbf{F}^{\{0\}}$ \\
6 & & & $\mathbf{L}^{\{0\}} \mathbf{U}^{\{0\}} \mathbf{F}^{\{1\}}$ \\
7 & Simplifying assumptions & & $\mathbf{L}^{\{1\}} \mathbf{H}^{\{0\}} \mathbf{U}^{\{0\}} \mathbf{F}^{\{0\}}$ \\
\hline
\end{tabular}

$\mathbf{A}^{\{0\}} \mathbf{B}^{\{1\}} \mathbf{D}^{\{1\}} \mathbf{E}^{\{1\}}$ is an easy counterfactual because it is highly plausible that $\mathbf{O}^{\{1\}}$ would also be observed if such as configuration existed.

In contrast, the second intermediate solution, $\mathbf{A}^{\{0\}} \mathbf{B}^{\{1\}} \mathbf{E}^{\{0\}}$, results from the addition of $\mathbf{A}^{\{0\}} \mathbf{B}^{\{1\}} \mathbf{D}^{\{0\}} \mathbf{E}^{\{0\}}$ to the output function of the conservative solution. If $\mathbf{A}^{\{0\}} \mathbf{B}^{\{1\}} \mathbf{D}^{\{1\}} \mathbf{E}^{\{0\}}$ is associated with $\mathbf{O}^{\{1\}}$, then any configuration that only differs on $\mathbf{D}$ in that $\mathbf{D}^{\{1\}}$ is replaced by $\mathbf{D}^{\{0\}}$ cannot be associated with $\mathbf{O}^{\{1\}}$ according to the directional expectation formulated above. The remainder configuration $\mathbf{A}^{\{0\}} \mathbf{B}^{\{1\}} \mathbf{D}^{\{0\}} \mathbf{E}^{\{0\}}$ is a difficult counterfactual because it is highly implausible that $\mathbf{O}^{\{1\}}$ would be have been observed in its presence.

(Sager and Andereggen 2012, p. 67f.) provide directional expectations for all five contextual condition factors before they derive the parsimonious solution. Explicitly or implicitly by referring to existing knowledge about a condition's effect, they conjecture that a high degree of acceptance results if a project is implemented at the federal level $\left(\mathbf{L}^{\{2\}}\right)$, has a prior history $\left(\mathbf{H}^{\{1\}}\right)$, is located in the German-speaking part of Switzerland $\left(\mathbf{G}^{\{1\}}\right)$, is located in less urbanized areas $\left(\mathbf{U}^{\{0\}}\right)$ and has plentiful resources $\left(\mathbf{F}^{\{1\}}\right)$. The resulting conservative, parsimonious and intermediate solutions are given in the upper part of Table 4.

Under the conservative solution, $S_{\mathrm{CO}}$, projects in German-speaking parts have always met with a high degree of acceptance when they were implemented at the cantonal level, and had a prior history as well as financial support, or when they had no prior history and no financial support, but were located in urbanized areas, or when they were implemented at the federal level in non-urbanized areas and had no prior history. In addition, high project acceptance resulted independent of language region when the project was implemented at the municipal level in an urbanized area, had a prior history and was financially well-supported. 
In contrast, the parsimonious solution, $S_{\mathrm{PA}}$, suggests that projects have always met with a high degree of acceptance when they were implemented at the federal level, or had no prior history and no financial support, or were implemented at the municipal level and had financial support, or when they were located in German-speaking areas, had a prior history and financial support. ${ }^{19}$ Between these two extremes, the intermediate solution states that projects in German-speaking parts have always met with a high degree of acceptance when they were implemented at the federal level and located in non-urban areas, or when they had plentiful resources and a prior history, or even when they had to make do with scarce finances, had no history but were located at the cantonal level. In addition, projects at the town or municipal level have been readily accepted provided that they were financially wellsupported and had a prior history.

The lower part of Table 4 lists the minimized expressions of the simplifying assumptions that have entered the derivation of the parsimonious solution, and the minimized expressions of the easy counterfactuals from the set of simplifying assumptions that have entered the derivation of the intermediate solution. In the two subsections of the following section, I demonstrate how to obtain these solutions in the QCA package and well as by manual derivation.

\section{Deriving intermediate solutions and summary statistics}

Support for intermediate solutions as well as consistency and coverage statistics in mvQCA is available in the QCA package for the $R$ environment (Thiem and Duşa 2013a,b,c). $R$ is a powerful stand-alone command-line interface program for statistical computing and graphics to which further functionality can be added via individual packages ( $\mathrm{R}$ Development Core Team 2013). ${ }^{20}$ The QCA package should first be downloaded and installed before being loaded into the workspace of a session. This is most easily achieved from within the RGui window (Packages $\rightarrow$ Install package $(s)$...) or via download from its official website at http:// cran.r-project.org/ and subsequent installation from within the RGui window (Packages $\rightarrow$ Install package(s) from local zip files...).

\subsection{Computational derivation with the QCA package}

The QCA package offers all necessary procedures for deriving intermediate solutions automatically through the provision of directional expectations. But first, it has to be installed and loaded into a current $\mathrm{R}$ session. By loading a package through R's library ( ) function, it is made available for use. After the QCA package has been loaded, the dataset has to be imported if it is not created directly within R. Figure 2 shows the RGui window, in which the $\mathrm{R}$ console and the script editor window are integrated, and how to employ the basic $\mathrm{R}$ function read. CSV ( ) for importing comma-separated value files. ${ }^{21}$

Once the dataset has been imported and assigned to an object variable (sa), QCA's truthTable () function should be invoked to construct the truth table ( $t$ ). This is achieved by passing the object holding the dataset, the names of the conditions (cond) and the name of the outcome (A) to the function as shown in Fig. 3. The logical but optional

\footnotetext{
19 Note that this solution corrects the one presented by (Sager and Andereggen 2012, 70).

20 At the time of writing, 5065 extension packages were available.

21 CSV files are very convenient, not least because they can also be read by the fs/QCA and Tosmana software.
} 


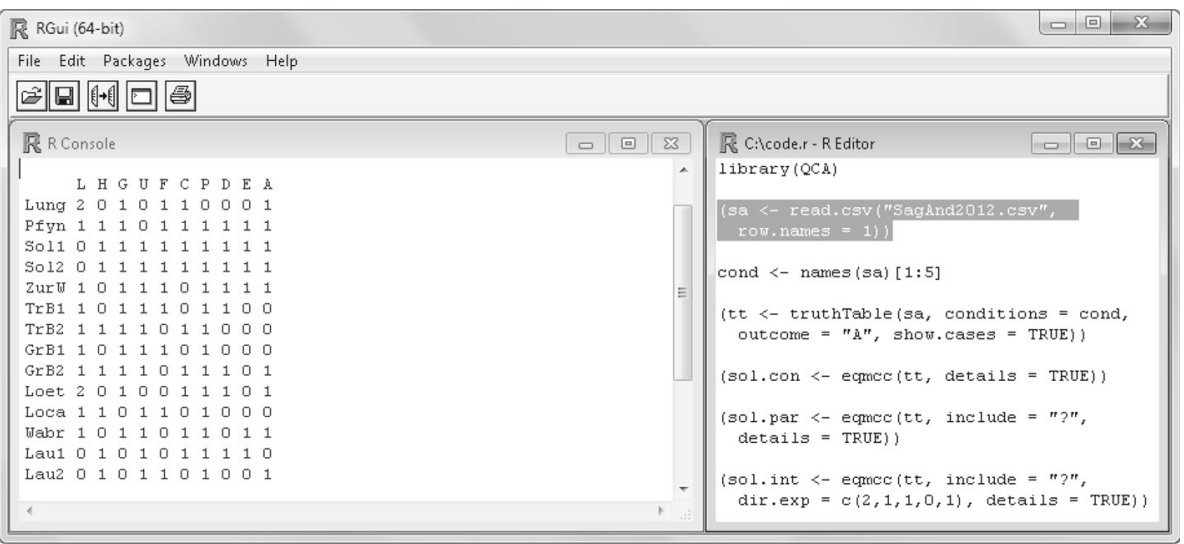

Fig. 2 RGui, R console, R script editor and transport project dataset

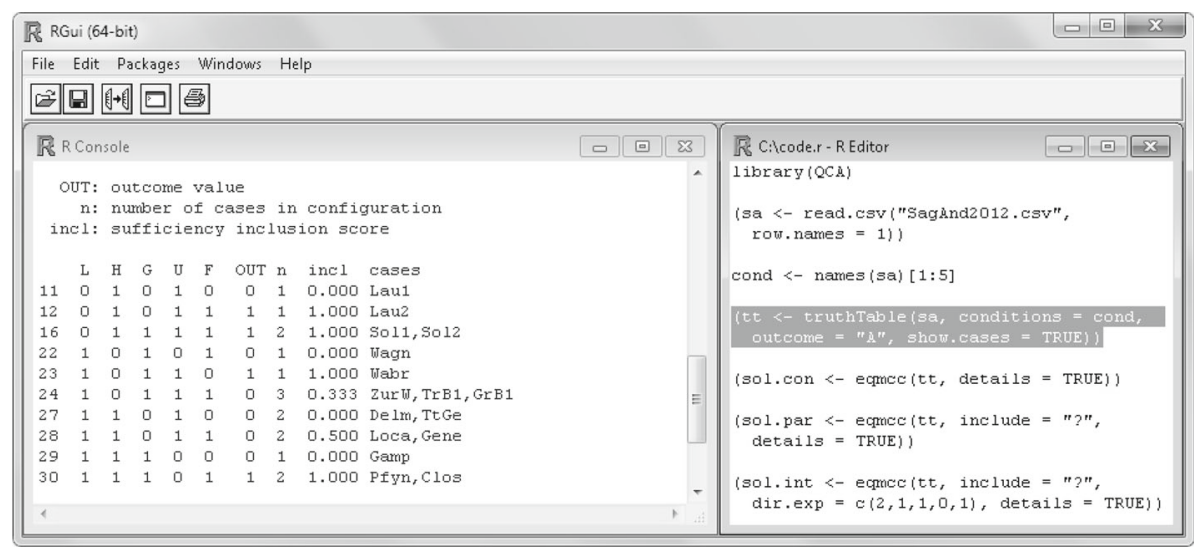

Fig. 3 QCA truth table of transport projects

argument show. cases controls whether the case names should be printed next to their respective configuration. ${ }^{22}$ The truth table presented in Fig. 3 is exactly the same as the truth table shown in Table 3 above. Note, however, that consistency is called inclusion (incl) in the QCA package. ${ }^{23}$ In addition, QCA uses a fixed procedure for building truth tables, which is why configuration line numbers in the first column do not necessarily follow a natural order beginning with 1 at increments of 1 .

After the truth table has been specified and evaluated by the analyst, the conservative ( $\mathrm{s}$ l. con) and parsimonious solutions ( $\mathrm{sol}$. par) can be derived as depicted in Figs. 4 and 5. The eqmec ( ) function performs the minimization of the information contained in the truth table. At a minimum, it thus requires a truth table object. The logical but optional argument details causes a table with all parameters of fit to be printed in addition to the solution. The include argument accepts a vector of function values. Most importantly, this

22 The object cond is a user-defined character vector containing the names of the conditions to be included. It is subset to the first five names since sa contains both proximate and remote condition factors.

23 Consistency has been traditionally referred to as inclusion in the literature (Smithson 2005; Smithson and Verkuilen 2006). 


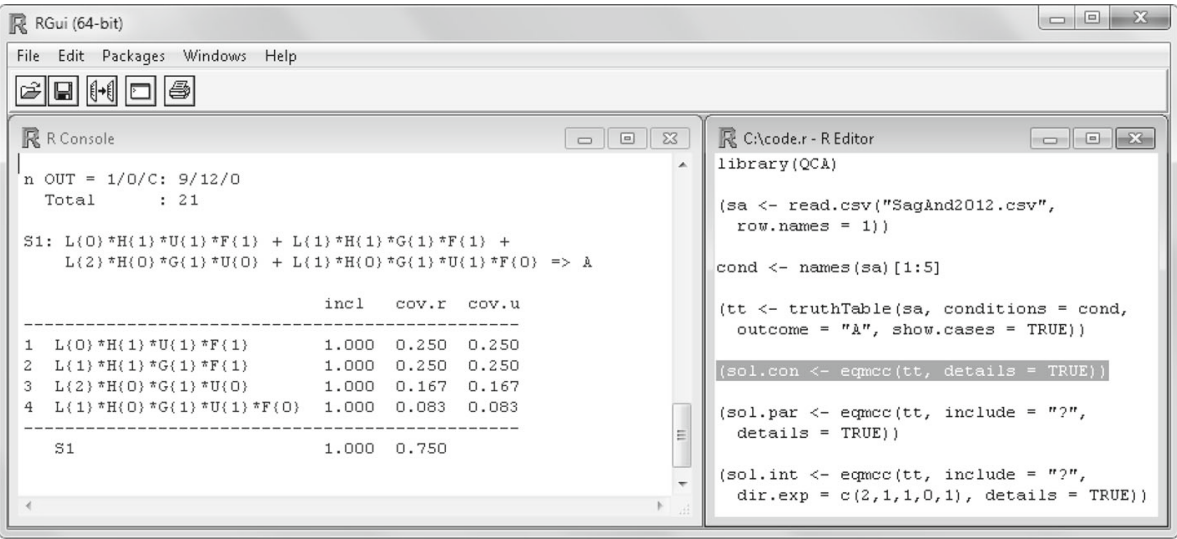

Fig. 4 QCA output, conservative solution, with inclusion and coverage statistics

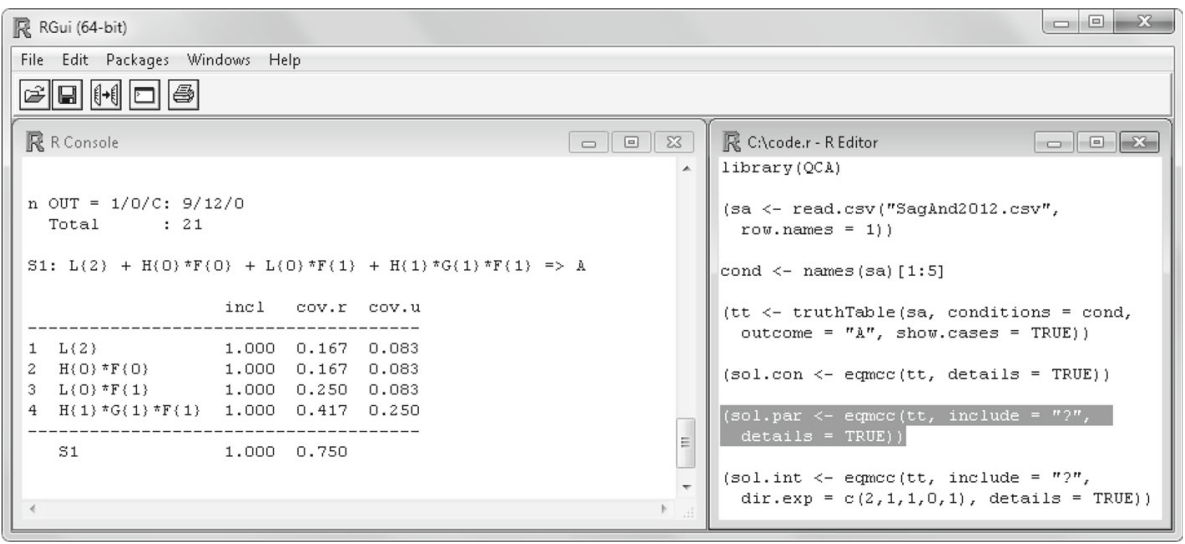

Fig. 5 QCA output, parsimonious solution, with inclusion and coverage statistics

argument can be used to include logical remainders, which are denoted by a question mark ("?"). ${ }^{24}$

Figure 6 shows how to derive intermediate solutions. In fact, conservative and parsimonious solutions need not be derived explicitly by the analyst before the intermediate solution can be found. This has only been done in this section for demonstration purposes. If the analyst specifies directional expectations via the dir . exp argument in the call to the eqmec ( ) function, QCA automatically produces the intermediate solution, with all information about the conservative and parsimonious solution stored in the solution object (sol. int). Since each intermediate solution is derived from a unique combination of exactly one conservative and one parsimonious solution, the existence of multiple solutions, conservative or parsimonious, gives rise to multiple intermediate solutions for the same set of directional expectations. These intermediate solutions may or may not be identical. For this reason, each intermediate solution output is augmented by information about the respective pair of the conservative and

24 The full truth table including logical remainders can be obtained by passing the optional argument complete = TRUE to the truthTable ( ) function. 


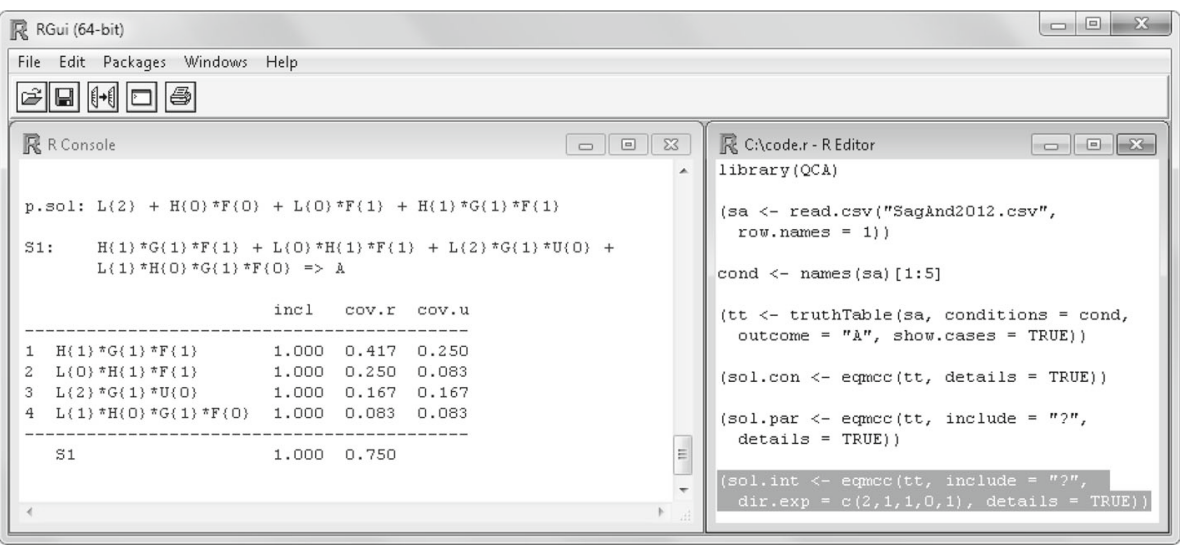

Fig. 6 QCA output, intermediate solution, with inclusion and coverage statistics

parsimonious solution from which it has been derived (p. sol). ${ }^{25}$ Figures 4, 5, 6 also show that when details = TRUE, not only the solution will be printed but also inclusion, raw $(\mathrm{COV} . \mathrm{r})$ and unique coverage scores ( $\mathrm{COV} \cdot \mathrm{u}$ ) for each prime implicant individually and the overall solution. $^{26}$

\subsection{Manual derivation with Veitch-Karnaugh maps}

The capabilities of the QCA package are leveraged via a command-line interface, but many social scientists feel more comfortable with graphical user interface software such as Tosmana or fs/QCA. However, the former lacks functionality for both parameters of fit as well as intermediate solutions and the latter cannot yet process mvQCA. In this section, I show how a generalization of the Veitch-Karnaugh map (VKM) developed in switching circuit theory can be used for solving set-theoretic minimization problems of low to moderate complexity (between two and five condition factors, depending on the number of factor levels). In essence, VKMs are conveniently arranged graphical representations of truth tables that are more conducive to the manual minimization of output functions than algebraic formulations (Hohn 1966, pp. 170-194; McCluskey 1965, pp. 114-131). In this section, I demonstrate how to derive conservative, parsimonious and intermediate solutions with VKMs, how to compute consistency scores for initial configurations as well as consistency and coverage scores for all three solution types.

The VKM depicted in Table 5 shows the positive (o) and negative configurations (•) of the truth table as single cells, together with the number of cases that also exhibit the outcome in the superscript and the number of cases that do not exhibit the outcome in the subscript for positive configurations and vice versa for negative ones. For example, the configuration $\mathbf{L}^{\{0\}} \mathbf{H}^{\{1\}} \mathbf{G}^{\{1\}} \mathbf{U}^{\{1\}} \mathbf{F}^{\{1\}}$ contains two cases of $\mathbf{A}^{\{1\}}$ and no case of $\mathbf{A}^{\{0\}}$. As a result, its consistency with respect to $\mathbf{A}^{\{1\}}$ is given by $\operatorname{Con}_{\mathbf{S}}\left(\mathbf{L}^{\{0\}} \mathbf{H}^{\{1\}} \mathbf{G}^{\{1\}} \mathbf{U}^{\{1\}} \mathbf{F}^{\{1\}} \subseteq\right.$ $\left.\mathbf{A}^{\{1\}}\right)=2 /(2+0)=1$. In contrast, the configuration $\mathbf{L}^{\{1\}} \mathbf{H}^{\{1\}} \mathbf{G}^{\{0\}} \mathbf{U}^{\{1\}} \mathbf{F}^{\{0\}}$ contains two cases of $\mathbf{A}^{\{0\}}$, but no case of $\mathbf{A}^{\{1\}}$. Its consistency with respect to $\mathbf{A}^{\{1\}}$ is therefore given by

25 The parsimonious solution will always be printed. However, as there is only one conservative solution in this example, it is not printed again.

26 Raw coverage scores correspond to the coverage statistic introduced in Sect. 3. Unique coverage scores take into account the overlap in coverage between different prime implicants. See Ragin (2006) for more details. 
L

\begin{tabular}{|c|c|c|c|c|c|c|c|c|}
\hline \multirow[b]{3}{*}{$\underline{\mathbf{1}}$} & \multirow[b]{3}{*}{ G } & \multirow[b]{2}{*}{0} & \multicolumn{2}{|c|}{0} & \multicolumn{2}{|c|}{1} & \multicolumn{2}{|c|}{$\underline{\boldsymbol{2}}$} \\
\hline & & & + & $\bullet \frac{1}{0}$ & $\bullet 1$ & $\times$ & - & - \\
\hline & & $\{\underline{\mathbf{1}}\}$ & + & $\bullet_{0}^{2}$ & $\bullet{ }_{1}^{1} \quad \bullet_{0}^{1}$ & $\bullet_{0}^{2}$ & + & + \\
\hline \multirow[t]{6}{*}{0} & G & $\{\underline{\mathbf{1}}\}$ & - & - & $\bullet \bullet_{1}^{2}$ & $\bullet \bullet_{0}^{1}$ & $\bullet \bullet_{0}^{1}$ & + \\
\hline & & $\{0\}$ & - & - & - & $x$ & - & - \\
\hline & & & $\{0\} \quad\{\underline{\mathbf{1}}\}$ & $\{\underline{\mathbf{1}}\} \quad\{0\}$ & $\{0\} \quad\{\underline{\mathbf{1}}\}$ & $\{\underline{\mathbf{1}}\} \quad\{0\}$ & $\{0\} \quad\{\underline{\mathbf{1}}\}$ & $\{\underline{\mathbf{1}}\} \quad\{0\}$ \\
\hline & & & $\mathbf{F}$ & F & F & F & $\mathbf{F}$ & $\mathbf{F}$ \\
\hline & & & $\{\underline{\mathbf{0}}\}$ & $\{1\}$ & $\{1\}$ & $\{\underline{0}\}$ & $\{\underline{0}\}$ & $\{1\}$ \\
\hline & & & & & & & I & \\
\hline
\end{tabular}

$\bullet_{n}^{p} / \circ_{n}^{p}$

/ / /

neg. / pos. configurations with neg. $(n)$ and pos. $(p)$ number of cases conservative / intermediate / parsimonious solution

difficult / easy counterfactual

$-1+$

$\times$

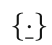

directional expectation

$\operatorname{Con}_{\mathrm{S}}\left(\mathbf{L}^{\{1\}} \mathbf{H}^{\{1\}} \mathbf{G}^{\{0\}} \mathbf{U}^{\{1\}} \mathbf{F}^{\{0\}} \subseteq \mathbf{A}^{\{1\}}\right)=0 /(2+0)=0$. Two configurations show maximally ambiguous consistency $\left(\mathbf{L}^{\{1\}} \mathbf{H}^{\{1\}} \mathbf{G}^{\{0\}} \mathbf{U}^{\{1\}} \mathbf{F}^{\{1\}}\right.$ and $\mathbf{L}^{\{1\}} \mathbf{H}^{\{1\}} \mathbf{G}^{\{1\}} \mathbf{U}^{\{1\}} \mathbf{F}^{\{0\}}$ ), whereas one configuration $\left(\mathbf{L}^{\{1\}} \mathbf{H}^{\{0\}} \mathbf{G}^{\{1\}} \mathbf{U}^{\{1\}} \mathbf{F}^{\{1\}}\right.$ ) contains more positive than negative evidence, but does not reach a level that would be justifiable with only three instances. Once the output function coding on the basis of each configuration's consistency score has been completed, the graphical minimization procedure of VKMs comes into play. It works as follows: minimization is only possible across adjacent cells within each block formed by one level of $\mathbf{L}$, or across all blocks formed by the levels of $\mathbf{L}$ on exactly the same position. Thus, adjacency that qualifies for minimization can be given both within as well as across the borders of a single block. The iterative application of this principle to the positive configurations first leads to the minimal union of the conservative solution.

Within block $\mathbf{L}^{\{0\}}, \mathbf{H}^{\{1\}} \mathbf{G}^{\{0\}} \mathbf{U}^{\{1\}} \mathbf{F}^{\{1\}}$ and $\mathbf{H}^{\{1\}} \mathbf{G}^{\{1\}} \mathbf{U}^{\{1\}} \mathbf{F}^{\{1\}}$ can be combined vertically to eliminate $\mathbf{G}$ and form the implicant $\mathbf{H}^{\{1\}} \mathbf{U}^{\{1\}} \mathbf{F}^{\{1\}}$. No further reduction across blocks is possible because a logical remainder occupies the position of $\mathbf{H}^{\{1\}} \mathbf{G}^{\{0\}} \mathbf{U}^{\{1\}} \mathbf{F}^{\{1\}}$ in $\mathbf{L}^{\{1\}}$ and two remainders the position of $\mathbf{H}^{\{1\}} \mathbf{U}^{\{1\}} \mathbf{F}^{\{1\}}$ in $\mathbf{L}^{\{2\}}$. Thus, $\mathbf{L}^{\{0\}} \mathbf{H}^{\{1\}} \mathbf{U}^{\{1\}} \mathbf{F}^{\{1\}}$ is the first prime implicant of the conservative solution. In block $\mathbf{L}^{\{1\}}$, configurations $\mathbf{H}^{\{1\}} \mathbf{G}^{\{1\}} \mathbf{U}^{\{0\}} \mathbf{F}^{\{1\}}$ and $\mathbf{H}^{\{1\}} \mathbf{G}^{\{1\}} \mathbf{U}^{\{1\}} \mathbf{F}^{\{1\}}$ can be simplified to $\mathbf{L}^{\{1\}} \mathbf{H}^{\{1\}} \mathbf{G}^{\{1\}} \mathbf{F}^{\{1\}}$, which represents the second prime implicant. For configuration $\mathbf{L}^{\{1\}} \mathbf{H}^{\{0\}} \mathbf{G}^{\{1\}} \mathbf{U}^{\{1\}} \mathbf{F}^{\{0\}}$, no simplification is possible because it is surrounded only by negative and remainder configurations. In $\mathbf{L}^{\{2\}}, \mathbf{H}^{\{0\}} \mathbf{G}^{\{1\}} \mathbf{U}^{\{0\}} \mathbf{F}^{\{0\}}$ and $\mathbf{H}^{\{0\}} \mathbf{G}^{\{1\}} \mathbf{U}^{\{0\}} \mathbf{F}^{\{1\}}$ can be reduced to $\mathbf{H}^{\{0\}} \mathbf{G}^{\{1\}} \mathbf{U}^{\{0\}}$ to yield $\mathbf{L}^{\{2\}} \mathbf{H}^{\{0\}} \mathbf{G}^{\{1\}} \mathbf{U}^{\{0\}}$ as the fourth prime implicant. This solution corresponds to $S_{\mathrm{CO}}$ given in Table 4 and Fig. 4 above. For purposes of visual orientation, its four prime implicants are marked by a dark-grey cell background ( $\square$ ) in Table 5. 
The parsimonious solution is derived in the same way, but on the basis of the prime implicants of the conservative solution, not the initial configurations. Beginning in block $\mathbf{L}^{\{2\}}$, which contains no negative configurations, all logical remainders can be used for minimizing $\mathbf{L}^{\{2\}} \mathbf{H}^{\{0\}} \mathbf{G}^{\{1\}} \mathbf{U}^{\{0\}}$ to $\mathbf{L}^{\{2\}}$. Within $\mathbf{L}^{\{1\}}, \mathbf{H}^{\{0\}} \mathbf{G}^{\{1\}} \mathbf{U}^{\{1\}} \mathbf{F}^{\{0\}}$ can be combined vertically with $\mathbf{H}^{\{0\}} \mathbf{G}^{\{0\}} \mathbf{U}^{\{1\}} \mathbf{F}^{\{0\}}$ to eliminate $\mathbf{G}$, and subsequently horizontally with $\mathbf{H}^{\{0\}} \mathbf{U}^{\{0\}} \mathbf{F}^{\{0\}}$ to eliminate $\mathbf{U}$. Additionally, however, $\mathbf{H}^{\{0\}} \mathbf{F}^{\{0\}}$ is present across all levels of $\mathbf{L}$ and can therefore be merged further to eliminate this condition factor. The resulting prime implicant becomes $\mathbf{H}^{\{0\}} \mathbf{F}^{\{0\}}$. Respecting $\mathbf{H}^{\{1\}} \mathbf{G}^{\{1\}} \mathbf{F}^{\{1\}}$, there are no further possibilities for reduction within the same block, but again across blocks so that $\mathbf{L}$ can be eliminated again to generate $\mathbf{H}^{\{1\}} \mathbf{G}^{\{1\}} \mathbf{F}^{\{1\}}$ as the third prime implicant of the parsimonious solution. Within block $\mathbf{L}^{\{0\}}, \mathbf{H}^{\{1\}} \mathbf{U}^{\{1\}} \mathbf{F}^{\{1\}}$ can be combined horizontally with $\mathbf{H}^{\{1\}} \mathbf{U}^{\{0\}} \mathbf{F}^{\{1\}}$ to eliminate $\mathbf{U}$, and then vertically with $\mathbf{H}^{\{0\}} \mathbf{F}^{\{1\}}$ to eliminate $\mathbf{H}$. L cannot be eliminated because there are three negative configurations on the same position in block $\mathbf{L}^{\{1\}}$. As a result, the fourth prime implicant is given by $\mathbf{L}^{\{0\}} \mathbf{F}^{\{1\}}$. This solution corresponds to $S_{\text {PA }}$ given in Table 4 and Fig. 5 above. Its four prime implicants are marked by a light-grey cell background $(\square)$.

The derivation of the intermediate solution on the basis of the conservative and the parsimonious solution now proceeds as follows. First, each condition for which a directional expectation has been formulated is marked in bold font-weight and underlined for easier orientation $\left(\mathbf{L}^{\{\underline{\mathbf{2}}\}}, \mathbf{H}^{\{\underline{\mathbf{1}}\}}, \mathbf{G}^{\{\underline{\mathbf{1}}\}}, \mathbf{U}^{\{\underline{\mathbf{0}}\}}, \mathbf{F}^{\{\underline{\mathbf{1}}\}}\right)$. Second, adjacent terms for each prime implicant from the conservative solution that are also supersets of the simplifying assumptions and accord to directional expectations have to be identified. When this process is completed, the set of easy counterfactuals will have been formed and the intermediate solution can be derived.

Beginning in block $\mathbf{L}^{\{2\}}, \mathbf{H}^{\{0\}} \mathbf{G}^{\{1\}} \mathbf{U}^{\{0\}}$ can be combined vertically with $\mathbf{H}^{\{1\}} \mathbf{G}^{\{1\}} \mathbf{U}^{\{0\}}$ because a prior history is expected to lead to a positive outcome, but no other reductions are possible. Thus, the first prime implicant of the intermediate solution is $\mathbf{L}^{\{2\}} \mathbf{G}^{\{1\}} \mathbf{U}^{\{0\}}$. In block $\mathbf{L}^{\{0\}}, \mathbf{H}^{\{1\}} \mathbf{U}^{\{1\}} \mathbf{F}^{\{1\}}$ can be combined horizontally with $\mathbf{H}^{\{1\}} \mathbf{U}^{\{0\}} \mathbf{F}^{\{1\}}$ because high project acceptance is expected in less urbanized areas, in contrast to the absence of a prior history. In consequence, $\mathbf{L}^{\{0\}} \mathbf{H}^{\{1\}} \mathbf{F}^{\{1\}}$ becomes the second prime implicant of the intermediate solution.

In the transition from the conservative to the parsimonious solution, condition factor $\mathbf{L}$ has been eliminated from $\mathbf{L}^{\{1\}} \mathbf{H}^{\{1\}} \mathbf{G}^{\{1\}} \mathbf{F}^{\{1\}}$, but since only projects at the federal level are expected to generate a positive outcome, whereas no high project acceptance is expected at the municipal level, the counterfactual implicant $\mathbf{L}^{\{2\}} \mathbf{H}^{\{1\}} \mathbf{G}^{\{1\}} \mathbf{F}^{\{1\}}$ is plausible, but not $\mathbf{L}^{\{0\}} \mathbf{H}^{\{1\}} \mathbf{G}^{\{1\}} \mathbf{F}^{\{1\}}$. However, it is important to note that implausibility with respect to one particular prime implicant does not imply general implausibility with respect to all prime implicants. In fact, there is an overlap in simplifying assumptions for two prime implicants from the parsimonious solution. The simplifying assumption $\mathbf{L}^{\{0\}} \mathbf{H}^{\{1\}} \mathbf{G}^{\{1\}} \mathbf{U}^{\{0\}} \mathbf{F}^{\{1\}}$ has already been identified as an easy counterfactual with respect to $\mathbf{L}^{\{0\}} \mathbf{H}^{\{1\}} \mathbf{F}^{\{1\}}$, so it cannot be barred from being included in the output function of the intermediate solution. This means that it becomes available for integration with $\mathbf{L}^{\{1\}} \mathbf{H}^{\{1\}} \mathbf{G}^{\{1\}} \mathbf{F}^{\{1\}}$ without being directly derivable from it. As a result, $\mathbf{H}^{\{1\}} \mathbf{G}^{\{1\}} \mathbf{F}^{\{1\}}$ becomes the third prime implicant.

$\mathbf{H}^{\{0\}} \mathbf{F}^{\{0\}}$ remains as the last prime implicant of the parsimonious solutions. As less urbanized areas are expected to contribute to high project acceptance, $\mathbf{L}^{\{1\}} \mathbf{H}^{\{0\}} \mathbf{G}^{\{1\}} \mathbf{U}^{\{0\}} \mathbf{F}^{\{0\}}$ is an easy counterfactual and serves to eliminate $\mathbf{U}$ to yield $\mathbf{L}^{\{1\}} \mathbf{H}^{\{0\}} \mathbf{G}^{\{1\}} \mathbf{F}^{\{0\}}$. The condition factor $\mathbf{G}$, in contrast, cannot be eliminated because projects located in non-German-speaking areas are not expected to contribute to high project acceptance. And although $\mathbf{L}^{\{2\}} \mathbf{H}^{\{0\}} \mathbf{G}^{\{1\}} \mathbf{U}^{\{1\}} \mathbf{F}^{\{0\}}$ would be available as an easy counterfactual in the possible elimination of condition factor $\mathbf{L}$, the negative expectation about $\mathbf{L}^{\{0\}}$ prevents a further reduction. In consequence, $\mathbf{L}^{\{1\}} \mathbf{H}^{\{0\}} \mathbf{G}^{\{1\}} \mathbf{F}^{\{0\}}$ represents the fourth prime implicant of the intermediate solution. As the 
foregoing example shows, there may be situations in mvQCA when easy counterfactuals do not contribute to a more parsimonious solution because certain configurations which include conditions that are not positively associated with the outcome prevent their use in deriving simpler expressions. ${ }^{27}$

After the intermediate solution has been derived, consistency and coverage scores can be calculated using Eqs. (10) and (11). Since no cell in Table 5 that represents a positive configuration contains any negative cases, each prime implicant, and in consequence also the solution, shows a perfect consistency score. In total, there are 12 positive cases, so the coverage scores for the four prime implicants of the intermediate solution are given by $5 / 12 \approx$ 0.417 for $\mathbf{H}^{\{1\}} \mathbf{G}^{\{1\}} \mathbf{F}^{\{1\}}, 3 / 12=0.25$ for $\mathbf{L}^{\{0\}} \mathbf{H}^{\{1\}} \mathbf{F}^{\{1\}}, 2 / 12 \approx 0.167$ for $\mathbf{L}^{\{2\}} \mathbf{G}^{\{1\}} \mathbf{U}^{\{0\}}$ and $1 / 12 \approx 0.083$ for $\mathbf{L}^{\{1\}} \mathbf{H}^{\{0\}} \mathbf{G}^{\{1\}} \mathbf{F}^{\{0\}}{ }^{28}$

\section{Conclusion}

Consistency and coverage as the two most important parameters of fit as well as intermediate solutions as a strategy to discriminate between easy and difficult counterfactuals have become established features in csQCA and fsQCA. While unwarranted scepticism about mvQCA's set-theoretic status has contributed to its undervaluation, it has also been left behind its two sister variants due to the unavailability of methodological advances that both csQCA and fsQCA could offer to users. This article has introduced two innovations. First, I have generalized consistency and coverage to models that include multivalent condition and/or outcome factors. And second, I have imported the concept of the intermediate solution to mvQCA. In consequence, and at least from a technical point of view, the method is now fully on a par with csQCA and fsQCA. Whether or not the presence of these new features will in turn lead to more even application ratios between different QCA variants also depends on the enthusiasm of methodologists and instructors to extend their research and teaching repertoire in this direction.

In order to demonstrate how to make practical use of the innovations introduced in this article, I have reviewed the QCA software, a highly versatile command-line package for the $\mathrm{R}$ environment. For users unfamiliar with QCA, I have presented a manual alternative in the form of generalized Veitch-Karnaugh maps. Although the use of software should certainly be favoured, it is not impractical to apply such maps for set-theoretic problems of low to moderate complexity.

With these new possibilities now in place, the range of analytical procedures for prospective users of mvQCA has expanded considerably, and with it, the attractiveness of the method for conducting configurational comparative research. If these opportunities become duly recognized, mvQCA should soon be stepping out of the shadow of its two sister variants.

Acknowledgments I am grateful to Michael Baumgartner, Tim Haesebrouck and the two anonymous reviewers for very helpful comments and suggestions.

\footnotetext{
27 Whether or not such counterfactuals should then be included as part of the solution is a question to be discussed in future research. The default behaviour of the QCA package is to omit and record them as nonsimplifying counterfactuals.

28 Unique coverage scores for a prime implicant can be calculated as the number of all covered positive cases minus the cardinality of the union of all other prime implicants divided by the total number of positive cases. For example, $\mathbf{L}^{\{0\}} \mathbf{H}^{\{1\}} \mathbf{F}^{\{1\}}$ has a unique coverage of $(9-8) / 12 \approx 0.083$ because two of its cases are also covered by $\mathbf{H}^{\{1\}} \mathbf{G}^{\{1\}} \mathbf{F}^{\{1\}}$.
} 


\section{References}

Ackrén, M., Olausson, P.M.: Condition(s) for island autonomy. Int. J. Minor. Gr. Rights 15(2-3), 227-258 (2008)

Balthasar, A.: The effects of institutional design on the utilization of evaluation. Evaluation 12(3), 353-371 (2006)

Baumgartner, M.: Inferring causal complexity. Sociol. Methods Res. 38(1), 71-101 (2009)

Berg-Schlosser, D.: Determinants of democratic successes and failures in Africa. Eur. J. Polit. Res. 47(3), 269-306 (2008)

Cronqvist, L.: Tosmana: Tool for small-n analysis, version 1.3.2.0 [computer programme]. University of Trier, Trier, (2011)

Cronqvist, L., Berg-Schlosser, D.: Multi-value QCA (mvQCA). In: Rihoux, B., Ragin, C.C. (eds.) Configurational Comparative Methods: Qualitative Comparative Analysis (QCA) and Related Techniques, pp. 69-86. Sage, London (2009)

Delhi, V.S.K., Mahalingam, A., Palukuri, S.: Governance issues in BOT based PPP infrastructure projects in India. Built Environ. Proj. Asset. Manag. 2(2), 234-249 (2012)

Denk, T.: Comparative multilevel analysis: proposal for a methodology. Int. J. Soc. Res. Method. 13(1), 29-39 (2010)

Dubrova, E.: Multiple-valued logic synthesis and optimization. In: Hassoun, S., Sasao, T. (eds.) Logic Synthesis and Verification, pp. 89-114. Springer Science+Business Media, New York (2002)

Eliason, S.R., Stryker, R.: Goodness-of-fit tests and descriptive measures in fuzzy-set analysis. Sociol. Methods Res. 38(1), 102-146 (2009)

Gross, M., Garvin, M.: Structuring PPP toll-road contracts to achieve public pricing objectives. Eng. Proj. Organ. J. 1(2), 143-156 (2011)

Hartmann, C., Kemmerzell, J.: Understanding variations in party bans in Africa. Democratization 17(4), 642-665 (2010)

Herrmann, A.M., Cronqvist, L.: When dichotomisation becomes a problem for the analysis of middle-sized datasets. Int. J. Soc. Res. Method. 12(1), 33-50 (2009)

Hohn, F.E.: Applied Boolean Algebra: An Elementary Introduction, 2nd edn. Macmillan, New York (1966)

Huntjens, P., Pahl-Wostl, C., Rihoux, B., Schlüter, M., Flachner, Z., Neto, S., Koskova, R., Dickens, C.: Adaptive water management and policy learning in a changing climate: a formal comparative analysis of eight water management regimes in Europe, Africa and Asia. Environ. Policy Gov. 21(3), 145-163 (2011)

Jordan, E., Gross, M.E., Javernick-Will, A.N., Garvin, M.J.: Use and misuse of Qualitative Comparative Analysis. Constr. Manag. Econ. 29(11), 1159-1173 (2011)

Klüver, H.: Europeanization of lobbying activities: when national interest groups spill over to the European level. J. Eur. Integr. 32(2), 175-191 (2010)

Mannewitz, T.: Alte Bekannte im neuen System: Gründe für die Aufstiege und Niedergänge der mittelosteuropäischen Postkommunisten seit 1990. Zeitschrift für Vergleichende Politikwissenschaft 4(2), 261-293 (2010)

McCluskey, E.J.: Introduction to the Theory of Switching Circuits. Princeton University Press, Princeton (1965)

R Development Core Team.: R: A Language and Environment for Statistical Computing. R Foundation for Statistical Computing, Vienna (2013)

Ragin, C.C.: The Comparative Method: Moving Beyond Qualitative and Quantitative Strategies. University of California Press, Berkeley (1987)

Ragin, C.C.: Fuzzy-Set Social Science. University of Chicago Press, Chicago (2000)

Ragin, C.C.: Set relations in social research: evaluating their consistency and coverage. Polit. Anal. 14(3), 291-310 (2006)

Ragin, C.C.: Redesigning Social Inquiry: Fuzzy Sets and Beyond. University of Chicago Press, Chicago (2008)

Ragin, C.C., Davey, S.: fs/QCA: Fuzzy-set/Qualitative Comparative Analysis, version 2.5 [computer programme]. Department of Sociology, University of Arizona, Tucson, AZ (2009)

Ragin, C.C., Sonnett, J.: Between complexity and parsimony: limited diversity, counterfactual cases and comparative analysis. In: Kropp, S., Minkenberg, M. (eds.) Vergleichen in der Politikwissenschaft, pp. 180-197. VS Verlag für Sozialwissenschaften, Wiesbaden (2005)

Rihoux, B.: Qualitative Comparative Analysis (QCA) and related systematic comparative methods: recent advances and remaining challenges for social science research. Int. Sociol. 21(5), 679-706 (2006)

Rihoux, B., Álamos Concha, P.: From niche to mainstream method? A comprehensive mapping of QCA applications in journal articles from 1984 to 2011. Polit. Res. Quart. 66(1), 175-184 (2013)

Rohlfing, I.: Analyzing multilevel data with QCA: a straightforward procedure. Int. J. Soc. Res. Method. 15(6), 497-506 (2012) 
Sager, F., Andereggen, C.: Dealing with complex causality in realist synthesis: the promise of Qualitative Comparative Analysis. Am. J. Eval. 33(1), 60-78 (2012)

Schneider, C.Q., Wagemann, C.: Set-theoretic Methods for the Social Sciences: A Guide to Qualitative Comparative Analysis (QCA). Cambridge University Press, Cambridge (2012)

Schneider, C.Q., Wagemann, C.: Doing justice to logical remainders in QCA: moving beyond the standard analysis. Polit. Res. Q. 66(1), 211-220 (2013)

Smithson, M.: Fuzzy set inclusion: linking fuzzy set methods with mainstream techniques. Sociol. Methods Res. 33(4), 431-461 (2005)

Smithson, M., Verkuilen, J.: Fuzzy Set Theory: Applications in the Social Sciences. SAGE, London (2006)

Thiem, A.: Clearly crisp, and not fuzzy: a reassessment of the (putative) pitfalls of multi-value QCA. Field Methods 25(2), 197-207 (2013a)

Thiem, A.: Unifying configurational comparative methods: Generalized-set Qualitative Comparative Analysis. Sociol. Methods Res. (2013b). doi:10.1177/0049124113500,481

Thiem, A., Duşa, A.: Boolean minimization in social science research: a review of current software for Qualitative Comparative Analysis (QCA). Soc. Sci. Comput. Rev. 31(4), 505-521 (2013a)

Thiem, A., Duşa, A.: QCA: a package for Qualitative Comparative Analysis. R J. 5(1), 87-97 (2013b)

Thiem, A., Duşa, A.: Qualitative Comparative Analysis with R: A User's Guide. Springer, New York (2013c)

Thiem A, Duşa A.: When more than time is of the essence: Enhancing the minimization of Boolean output functions with $e \mathrm{QMC}$. J. Math. Sociol. (forthcoming)

Vink, M.P., van Vliet, O: Not quite crisp, not yet fuzzy? Assessing the potentials and pitfalls of multi-value QCA. Field Methods 21(3), 265-289 (2009)

Vink, M.P., van Vliet, O: Potentials and pitfalls of multi-value QCA: response to Thiem. Field Methods 25(2), 208-213 (2013) 